\title{
Е.Г. Григорьев
}

\section{ГОСПИТАЛЬНАЯ ХИРУРГИЧЕСКАЯ КЛИНИКА}

\author{
ФГБНУ “Иркутский научный центр хирургии и травматологии», Иркутск, России \\ ФГБОУ ВО “Иркутский государственный медицинский университет» Минздрава России, Иркутск, России
}

Описана история создания и развития кафедры госпитальной хирургии Иркутского государственного медицинского университета с 1921 года. Дан анализ учебной и научной деятельности за 95 лет. Показана работа кафедры в различные исторические периоды, отражена роль заведующих. Подробно описана роль сотрудников кафедры в становлении и развитии целого ряда направлений лечебной деятельности, впервые внедрённых в Иркутской области. Дано представление о кафедре как о составной части научно-лечебнопедагогического комплекса. Отмечена преемственность поколений.

Ключевые слова: кафедра госпитальной хирургии, история, госпитальная хирургическая клиника, Иркутск

\section{HOSPITAL SURGICAL CLINIC}

\section{E.G. Grigoryev}

Irkutsk Scientific Center of Surgery and Traumatology, Irkutsk, Russia Irkutsk State Medical University, Irkutsk, Russia

The article reviews main stages of establishment and development of the Department of Hospital Surgery in different periods. We showed the role of heads and stuff of the department in the development of multipartial complex which aims at the unity of three components - to teach, to treat and to study.

The first head of the department and of the clinic of hospital surgery (1921-1931) was N.A. Sinakevich. It was a period of establishment of the department, its staffing, formation of clinical site and training calendar. V.G. Shipachyov was the head of the department from 1931 to 1952. During the Great Patriotic War, the work of the department was aimed at the needs of war time related to the problems of reconstruction surgery and treatment of traumatic injuries. After the war, the work of the department was dedicated to the problems of hypothyroidism, obliterating endarteritis, gastrointestinal and urgent surgery.

In 1953, Z.T. Senchillo-Yaverbaum became the head of the department. The work of the department was dedicated to gastrointestinal and pancreatic surgery, herniology, thyrophymas. Also the department included course of traumatology. In 1972, V.I. Astafiev became the head of the department. In this period, many young hopefuls started to work on the department. Also the research, treatment and educational complex was created on the base of the department, Regional Clinical Hospital and Siberian Branch of Academy of Medical Sciences USSR. While keeping the traditions of the department, V.I. Astafiev created new research and practice directions and special referral units - of cardiac, vascular, thoracic, purulent and urgent surgery, operative coloproctology, plastic surgery, diagnostic picture and X-ray surgery. Also the system of individual and collective training of surgical clerk.

In 1988-1993 Y.I. Morozov was the head of the department. The new direction of the work was the development of complex treatment of purulent soft tissue involvement in patients with diabetes.

From 1993, E.G. Grigoryev is the head of the department of hospital surgery and the Institute of Surgery.

Key words: department of hospital surgery, history, hospital surgical clinic, Irkutsk

Госпитальная клиника клиника обыденной жизни

В 2001 г. опубликована небольшая книга, касающаяся 80-летней истории госпитальной хирургической клиники Иркутского государственного медицинского университета [3]. Авторы (Е.Г. Григорьев, В.Л. Смирнов), сотрудники кафедры и студенты кружка госпитальной хирургии провели максимально возможный архивный поиск, что позволило говорить об исторической достоверности изложения. Вместе с тем стало понятно, что полностью рассказать о разнообразной деятельности сотрудников клиники, особенно ординаторов, среднего и младшего медицинского персонала, к сожалению, невозможно, однако удалось проследить основные этапы становления кафедры. В 2016 г. госпитальной хирургической клинике исполняется 95 лет, и мы вновь попытаемся коротко рассказать, как это было.

Итак, 13 августа 1918 г. «в городской управе состоялось заседание Думы с представителями общественных организаций и министром народного просвещения Сапожниковым, который в 7 часов 35 минут 10 секунд подписал акт об открытии Ир- кутского государственного университета, пока историко-филологического и юридического факультетов» (Н.С. Романов, чиновник городской управы). Позже был образован физико-математический факультет с медицинским отделением, которое в январе 1920 г. стало самостоятельным факультетом. Первая лекция для студентов-медиков была прочитана 16 октября 1919 г. профессором Н.Д. Бушмакиным. Медицинский факультет формировался преимущественно профессорами казанской и томской университетских школ. Одним из них был Н.А. Синакевич, который в апреле 1920 г. прибыл в Иркутск с 5-й Рабоче-крестьянской Красной Армией, где служил консультантом-хирургом.

По ходатайству ректора Н.Д. Бушмакина профессору Н.А. Синакевичу было поручено «принять на себя заведование организуемой при 3-м клиническом госпитале хирургической клиникой на базе Знаменской больницы». Точными датами открытия кафедры и клиники госпитальной хирургии являются 6 июня и 15 сентября 1921 г. соответственно.

Директором клиники стал Н.А. Синакевич, ассистентами - С.И. Тюменев, П.Н. Шастин, ординаторами - К.А. Заорский, И.В. Лепетнев, В.В. Шабанов. 
В 1922 г. состоялся переезд клиники из Знаменской больницы в Кузнецовскую. На кафедру пришли работать ассистенты Г.М. Берлинский, С.Г. Коноктин, ординаторы С.Я. Сегельман, Н.С. Епифанов. Врачей было мало, а больных - много.

В этот период Н.А. Синакевичем были написаны две книги - «Сифилис позвоночника» и «Туберкулезный перитонит» - небольшие по объёму, но актуальные и сегодня. Николай Александрович оставил кафедру в 1931 г., будучи против изменения учебной программы и ликвидации 5-го курса в медицинском институте. Впоследствии он возглавлял хирургическую клинику стоматологического института, а позднее руководил клиникой вновь образованного Иркутского института травматологии и ортопедии. Умер он 14 июля 1960 г. в Иркутске.

Профессор В.Г. Шипачёв перебрался в Иркутск из Томска. Он привёз с собой научно-медицинскую библиотеку, рентгеновские снимки, микроскопические препараты по хирургической патологии, таблицы, хирургические инструменты. Василий Герасимович стал заведующим кафедрой общей хирургии, которой руководил до 1931 г.

После он возглавил кафедру госпитальной хирургии, где, кроме него, работали ассистенты П.О. Фейтельберг, А.М. Мясников, П.А. Маценко, аспиранты В.С. Семёнов, Якубовская, Закутин, ординаторы Запунный, Ложкина, Гладких. Позднее на кафедру поступили Н.Ф. Юдин, П.П. Габышев, В.Ф. Ли, А.Н. Десков. Сотрудники кафедры активно занимались эндокринной патологией, изучением уровской болезни (Кашина - Бека) и добились заметных успехов [2].

С началом войны практически все ассистенты и доценты кафедры были мобилизованы в ряды Красной Армии.

Во время войны в Иркутске был создан отдел эвакогоспиталей, работа кафедры была переориентирована на потребности военного времени. Профессор В.Г. Шипачёв (вскоре лауреат Сталинской премии) и ассистент И.О. Васенина занимались разработкой проблемы реконструкции пальцев руки. В то же время Василий Герасимович приступил к работам «Ранения тазовых органов в условиях военного времени», «0 пересадке кожи на кость». Ассистент И.О. Васенина работала по теме «Перемещение пястных костей».

Профессор В.Г. Шипачёв был выдающейся личностью и блестящим хирургом широкого профиля.

По окончании войны в Иркутск и на кафедру вернулись бывшие военные врачи П.А. Маценко и Н.Ф. Юдин. В 1946-1952 гг. ассистентами стали П.Г. Пуляевский и А.В. Васюхина (в последующем - заведующая хирургическим отделением), которая в годы войны была начальником хирургического отделения эвакогоспиталя.

Сотрудники кафедры продолжали заниматься проблемами зоба и уровской болезни. Василий Герасимович Шипачёв активно привлекал студентов в летние экспедиции в эндемические очаги патологии.

В 1950-е гг. ассистентами кафедры стали 3.В. Андриевская и Э.М. Лифшиц. Зоя Васильевна Андриевская в годы войны служила ординатором, а затем командиром операционно-перевязочного взвода. Эмма Моисеевна Лифшиц была призвана в ряды Красной армии ещё в 1939 г., участвовала в войне с Финляндией в качестве хирурга полевого госпиталя, с 1941 г. служила военным хирургом медсанбата стрелковой дивизии.

С 1947 по 1953 гг. проработал на кафедре С.Т. Чекан, в годы войны служивший начальником хирургических отделений медслужбы Тихоокеанского флота. Степан Тимофеевич вёл курс военно-полевой хирургии, позднее стал доцентом кафедры факультетской хирургии. В 1960 г. после защиты докторской диссертации он возглавил кафедру.

Б.И. Чуланов во время гражданской войны был фельдшером в Первой конной армии Будённого С.М., в годы ВОВ служил начальником хирургических отделений ряда госпиталей. Стал ассистентом кафедры в 1952 г. Борис Иванович был пионером грудной хирургии. В должности доцента проработал до ухода на пенсию (1973 г.).

А.В. Серкина, хирург-ординатор Иркутской городской больницы № 1 , получила приглашение на кафедру в 1949 г. Тематика её научных исследований была не совсем традиционной для госпитальной клиники: облитерирующий эндартериит, который сначала именовался «траншейной стопой», а по источникам других исследователей - спонтанной или самопроизвольной гангреной. Впоследствии эта работа стала темой кандидатской и докторской диссертаций Александры Васильевны. В 1952 г. А.В. Серкина перешла на кафедру факультетской хирургии, а в 1972 г. возглавила кафедру общей хирургии.

В сентябре 1952 г. на кафедру была принята Е.И. Калиновская - хирург эвакогоспиталя в годы войны, ординатор городской больницы, заведующая райздравотделом города Тайшета, борт-хирург санитарной авиации, хирург областной клинической больницы, ведущий специалист в лечении пациентов с патологией щитовидной железы.

Что касается Василия Герасимовича Шипачёва, то с 1953 года он продолжил свою педагогическую и научную деятельность на кафедре факультетской хирургии. Скончался он в 1957 г. в своём рабочем кабинете в клинике.

С марта 1953 г. руководство кафедрой госпитальной хирургии перешло к ученице К.П. Сапожкова - 3.Т. Сенчилло-Явербаум. К этому времени Зинаида Тихоновна защитила кандидатскую диссертацию (1937 г.), работала доцентом на кафедре факультетской хирургии, готовила докторскую диссертацию на тему «Болезни оперированного желудка». Защита состоялась в 1955 г. в Ленинграде.

Зинаида Тихоновна - учёный с мировым именем. Её научные разработки были внедрены в практику не только отечественных, но и зарубежных хирургов. Она прошла замечательную научно-практическую школу профессора К.П. Сапожкова. Оперировала Зинаида Тихоновна классически и артистично, её операции не только были необходимой школой для хирургов, но и приносили эстетическое удовольствие. Блестящий результат достигался виртуозностью исполнения в чрезвычайно сложных анатомо-хирургических условиях.

Вместе с Зинаидой Тихоновной на кафедру госпитальной хирургии пришла ассистент В.И. Румянцева.

Под руководством 3.Т. Сенчилло-Явербаум исследовались проблемы желудочной хирургии (3.В. Андри- 
евская), хирургии пищевода, закрытой травмы головы (В.Г. Клейменов, Б.И. Чуланов, М.Б. Скворцов), герниологии, хирургии червеобразного отростка (Б.И. Чуланов), опухоли щитовидной железы (Е.И. Калиновская).

Также преподавание в это время осуществляли ассистенты В.Ф. Пирожков, М.Г. Мордухович, Е.Я. Черных. Кроме госпитальной хирургии, на кафедре были курсы стоматологии, костного туберкулёза, травматологии, военно-полевой хирургии.

В.Ф. Пирожков - выпускник 2-го Московского медицинского института им. Н.И. Пирогова - до прихода на кафедру работал хирургом областной клинической больницы. Сфера его интересов - желудочные кровотечения, хирургическое лечение портальной гипертензии, заболевания желчных протоков и поджелудочной железы. В этих разделах хирургии был лидером и достиг больших успехов.

Преподавание курса травматологии осуществлялось профессором З.В. Базилевской на базе НИИТО г. Иркутска, который она возглавляла.

В 1965 г. на кафедру после окончания аспирантуры пришёл ассистент Н.Р. Зеленин, который защитил кандидатскую диссертацию по проблеме хронического панкреатита, используя богатый клинический материал, полученный при работе в гастрохирургическом отделении областной больницы. Длительное время он был деканом 6-го курса лечебного факультета.

В 1963 г. аспирантом, а затем и ассистентом кафедры стал В.Г. Кочубей, до этого работавший главным врачом и хирургом Куйтунской ЦРБ. Он быстро защитил кандидатскую, а позднее докторскую диссертации, посвящённые дивертикулёзу двенадцатиперстной кишки. С 1981 г. работал заместителем директора ИФ ВСНЦ АМН СССР.

В конце 1970 г. на должность ассистента кафедры пришёл М.Б. Скворцов. Профессиональный путь Моисей Борисович начал в 1963 г. как хирург и главный врач Агинской участковой больницы Качугского района Иркутской области. В 1968 г. стал заведовать хирургическим отделением областной больницы.

Последними сотрудниками, принятыми на кафедру Зинаидой Тихоновной, были М.С. Чекан и П.Н. Викулин.

По окончании мединститута в 1961 г. Михаил Степанович Чекан работал хирургом участковой больницы села Голуметь. Впоследствии был ординатором областной туберкулезной больницы, факультетской хирургической клиники. Стал ассистентом кафедры в 1971 г., уже через полгода защитив кандидатскую диссертацию, посвящённую врождённым порокам сердца у детей. С переходом в клинику госпитальной хирургии М.С. Чекан начал оперировать на сердце (открытый артериальный проток) в областной клинической больнице, в течение 43 лет преподавал хирургию студентам 5-го и 6-го курсов.

Павел Николаевич Викулин - крупный торакальный и абдоминальный хирург - пришёл на кафедру из Иркутской дорожной больницы, где работал врачом отделения торакальной хирургии. В клинике стали систематически выполняться операции у пациентов снагноительными и опухолевыми заболеваниями лёгких, средостения. Павел Николаевич активно включился в работу кардиохирургического отделения. В 1976 г. переехал в Братск, где курировал торакальную службу.
Что касается Зинаиды Тихоновны СенчиллоЯвербаум, то после ухода на пенсию она долгое время работала консультантом в областной больнице. Скончалась в 1986 г.

В апреле 1972 г. заведующим кафедрой госпитальной хирургии стал Всеволод Иванович Астафьев, который сыграл выдающуюся роль не только в истории клиники, но и в развитии всех без исключения направлений хирургии Восточной Сибири. Всеволод Иванович окончил Курский медицинский институт. Работал хирургом районной больницы, Курской областной больницы, одиннадцать лет проработал на кафедре госпитальной хирургии Курского мединститута. Оперировал при болезнях желудка и пищевода, разработал технические приёмы, облегчающие хирургические вмешательства при раке прямой кишки, выполнял реконструктивные операции на почках, разрабатывал операции на брюшной аорте и магистральных артериях при облитерирующем атеросклерозе. Выполнил первые ангиографические исследования.

В Иркутске Всеволод Иванович поставил перед собой две первоочередные задачи: расширить клиническую базу кафедры и оснастить её современным оборудованием, а также привлечь к работе перспективную молодёжь из числа выпускников вуза. Восемь мест в клинической ординатуре на кафедре были заполнены выпускниками 1973 года.

Была расширена коечная база в главном корпусе областной больницы. На кафедру и в клинику пришли новые сотрудники. Преподавателями стали В.Н. Бойцов, Г.Н. Решетникова, А.Г. Сякерский, В.Е. Дьячков, Е.А. Пак.

Владилен Николаевич Бойцов (ученик Б.Д. Добычина) заведовал торакальным отделением железнодорожной больницы. Он был блестящим поливалентным хирургом, пионером кардиохирургии в Иркутске.

Галина Николаевна Решетникова до прихода на кафедру работала ординатором хирургического отделения областной клинической больницы. В 1975 г. защитила кандидатскую диссертацию. С 1982 г. и по настоящее время работает в Иркутском научном центре хирургии и травматологии, долгое время была учёным секретарём.

В.И. Астафьев уделял особое внимание специализации хирургии в клинике [1, 4]. Весной 1973 г. им были выполнены первые операции на сердце. В том же году на базе областной больницы был открыт межобластной кардиохирургический центр и областной центр рентгеноконтрастных методов исследования, которыми успешно занимался аспирант Ю.Н. Соколов. В 1975 г. он защитил кандидатскую диссертацию, касающуюся коронарографии при ишемической болезни сердца, с 1976 г. работал в Институте хирургии в Киеве (директор - А.А. Шалимов).

Было приобретено оборудование для эндоскопических исследований и открыт специализированный кабинет, работу которого курировали ассистенты М.Б. Скворцов и Е.Г. Григорьев.

В 1975 г. ассистент М.Б. Скворцов защитил кандидатскую диссертацию, которая предопределила дальнейшую направленность его исследований в области хирургии пищевода. Им разработаны оригинальные технические приёмы бужирования, собственные классификации рубцовых сужений пищевода и ме- 
тодики оперативного лечения, позволяющие с высокой эффективностью лечить короткие шейные и дистальные послеожоговые стриктуры. Внедрены в практику способы создания искусственного пищевода из целого желудка путём одномоментной операции в сочетании с удлинением всего трансплантата и наложением соустья на шее.

В 1991 г. Моисей Борисович защитил докторскую диссертацию на тему «Выбор оптимального способа лечения рубцовых сужений пищевода». Продолжает работать профессором кафедры и научным руководителем торакального отделения и центра хирургии пищевода.

Александр Григорьевич Сякерский начал работу на кафедре в 1971 г. В 1976 г. защитил кандидатскую диссертацию. Работал ассистентом до 1982 г., вёл занятия для субординаторов-хирургов на базе хирургического отделения Шелеховской городской больницы. Позднее возглавил редакционную группу Сибирского филиала ВНЦХ АМН СССР.

Евгений Авраамович Пак получил диплом врача в 1954 г., после чего окончил клиническую ординатуру и работал заведующим хирургическим отделением в Братске. Впервые стал выполнять операции по поводу болезни лёгких, гастрэктомиию, резекцию печени, операции при врождённых и приобретённых пороках сердца. В течение ряда лет Евгений Авраамович был главным хирургом Братска. В сентябре 1973 г. утверждён в должности главного хирурга Иркутской области, стал ассистентом кафедры общей хирургии, а в 1974 г. - доцентом кафедры госпитальной хирургии. Преподавание совмещал с работой главным хирургом области до 1983 г. На кафедре работал до 2012 г. Умер в 2015 г. на 85-м году жизни.

Особая роль с начала 70-х годов отводилась преподаванию хирургии в субординатуре. Кроме основной базы - Иркутской областной клинической больницы - использовались железнодорожная больница, больница авиазавода и Шелеховская городская больница. Институт субординатуры в системе подготовки врачей восстановлен в 1972 г., поэтому создание методологии работы с субординаторами-хирургами ИГМИ также следует отнести к заслугам В.И. Астафьева.

Всеволод Иванович разработал систему индивидуально-коллективной подготовки субординаторов. C каждой группой работал куратор из числа ассистентов кафедры. Назначался общественный декан потока. Много лет действовала система учебно-исследовательской работы студентов, которая явилась прочным фундаментом для будущих кандидатских диссертаций.

Через субординатуру и интернатуру кафедра подготовила свыше тысячи хирургов для Иркутской области [5].

В 1976-1977 гг. коллектив кафедры пополнился ассистентами Е.Г. Григорьевым и Ю.В. Желтовским, в 1979 г. - С.П. Чикотеевым.

Евгений Георгиевич Григорьев поступил в ИГМИ в 1967 г. В 1973 г. стал ординатором клиники госпитальной хирургии. Учился у П.Н. Викулина, В.Н. Ванеевой, Л.И. Калиновской, В.Л. Манна, Л.А. Матханова, А.Г. Сякерского, В.Ф. Пирожкова, М.Б. Скворцова, Н.В. Шинкарева, клинических ординаторов И.Г. Русакова, Н.В. Болдина и, конечно же, у В.И. Астафьева.
По предложению В.И. Астафьева, наряду с традиционной хирургией, Е.Г. Григорьев занимался эндоваскулярными и эндоскопическими методами в диагностике и лечении хирургических заболеваний. В 1983 г. защитил кандидатскую диссертацию.

Юрий Всеволодович Желтовский в сентябре 1973 г. стал клиническим ординатором кафедры госпитальной хирургии ИГМИ, куда его рекомендовал доцент В.Ф. Пирожков. За годы ординатуры Юрий Всеволодович получил общую хирургическую подготовку и освоил под руководством В.И. Астафьева операции на сердце. Защита кандидатской диссертации состоялась в 1982 г., докторской - в 2007 г. С 1979 по 1987 гг. был деканом потока субординаторов. С 2011 г. Юрий Всеволодович, оставаясь профессором кафедры госпитальной хирургии, заведует кафедрой ангиологии и сосудистой хирургии ИГМАПО.

Сергей Павлович Чикотеев также окончил мединститут в 1973 г. и стал интерном Железногорской ЦРБ. Затем работал в Жигаловской, Нукутской ЦРБ, где выполнил большое количество операций. В 1975 г. Сергей Павлович начал работать в отделении торакальной хирургии областной клинической больницы. В октябре 1980 г., став ассистентом, С.П. Чикотеев продолжал работать в торакальном отделении, а темой диссертационной работы была выбрана легочная хирургия.

В декабре 1983 г. С.П. Чикотеев назначен главным хирургом Иркутской области. В 1995 г. успешно защитил докторскую диссертацию.

По инициативе Всеволода Ивановича Астафьева с середины 1970-х гг. в клинике стала активно развиваться хирургия печени, поджелудочной железы, портальной гипертензии. Лидером этого направления остаётся С.П. Чикотеев, продолжая работать профессором кафедры.

В конце 1970-х - начале 1980-х гг. важным научным направлением кафедры стала рентгенэндоваскулярная хирургия. Разрабатывались диагностика и лечения заболеваний внутренних органов миниинвазивными методами. В 1976 г. в клинике впервые в СССР выполнена окклюзия бронхиальных артерий при лёгочном кровотечении, и эта процедура успешно применяется на протяжении 40 лет, что позволило существенно улучшить результаты лечения пациентов с этой патологией.

С февраля 1983 г. стал выполняться регионарный коронарный тромболизис при трансмуральном и крупноочаговом инфарктах миокарда, баллонная дилатация венечных сосудов при хронической ишемической болезни сердца (кандидатские диссертации Е.Я. Овчаренко, С.А. Атаманова, докторские диссертации А.А. Руновича, Т.Е. Курильской).

Эндоваскулярные вмешательства при желудочном кровотечении, заболеваниях печени и поджелудочной железы стали предметом диссертационного исследования А.И. Крапивы, К.К. Кан, А.И. Квашина, С.П. Чикотеева.

Существенно улучшило качество диагностики заболеваний органов груди и живота внедрение методов медицинской визуализации (УЗИ, КТ). Здесь успехов добился ещё один ученик Всеволода Ивановича - Виктор Анатольевич Шантуров, который защитил кандидатскую и докторскую диссертации. 
По инициативе и под руководством В.И. Астафьева и при поддержке академика Б.В. Петровского в 1973-1979 гг. проведена подготовительная работа по открытию на базе кафедры госпитальной хирургии ИГМИ объединённого с ней Сибирского филиала ВНЦХ АМН СССР.

Министр здравоохранения Б.В. Петровский впервые посетил кафедру осенью 1976 г. Он ознакомился с состоянием учебной, лечебной и научной работы. 27 мая 1981 г. министр здравоохранения подписал приказ № 572 «Об организации Сибирского филиала Всесоюзного научного центра хирургии Академии медицинских наук СССР, объединённого с кафедрой госпитальной хирургии Иркутского медицинского института».

В 1982 г. ассистентами кафедры стали В.Е. Пак и Е.Ф. Дубинин.

Владислав Евгеньевич Пак после окончания института работал в хирургическом отделении УстьИлимской ЦРБ. Став ассистентом кафедры, темой научной работы определил разработку хирургической тактики при двусторонних заболеваниях лёгких, осложнённых кровотечением. Диссертация успешно защищена в 1991 г.

Евгений Фёдорович Дубинин проходил интернатуру на базе медсанчасти авиазавода, с 1974 г. работал хирургом Чунской ЦРБ. В сентябре 1982 г. начал преподавательскую деятельность на кафедре, совмещая её с работой в гастрохирургическом отделении, где являлся одним из ведущих хирургов. Тогда же он стал бессменным борт-хирургом санавиации, сделав к 1999 г. свыше 350 вылетов в районы области.

В 1989 г. Евгений Фёдорович возглавил отделение экстренной хирургии областной клинической больницы, продолжая преподавать на кафедре.

В 1984 г. ассистентом кафедры стал П.Ш. Пипия. В 1982 г. он заведовал отделением гастрохирургии, в 1986 г. - отделением колопроктологии, а затем стал сотрудником Сибирского филиала ВНЦХ АМН СССР. 20 января 1984 г. Парнаози Шалвович успешно защитил в ИГМИ кандидатскую диссертацию по эндоскопической диагностике заболеваний желудка и двенадцатиперстной кишки.

В 1984 г. ассистентом кафедры была избрана Мария Владимировна Лазарева. Начав работать на кафедре, активно занималась научными исследованиями по проблеме осложнённых форм нагноительных заболеваний лёгких. Продолжает успешно работать в практическом здравоохранении.

Благодаря интеллекту, кругозору, организаторским способностям, неимоверной трудоспособности и харизматичности Всеволода Ивановича, к 1987 г. госпитальная хирургическая клиника, объединённая с филиалом ВНЦХ АМН СССР на базе областной больницы, стала поливалентным лечебно-научно-педагогическим комплексом, оснащённым современным оборудованием. Клинический полигон составил 385 коек (в 1972 г. - 90 коек). Эффективно работали отделения кардиохирургии, пластической и микрохирургии, торакальной, гнойной и неотложной хирургии, хирургической гастроэнтерологии, рентгенохирургических методов диагностики и лечения, эндоскопии, методов медицинской визуализации.
В 1987 г. В.И. Астафьев императивным решением бюро обкома партии без убедительной аргументации был освобождён от должностей заведующего кафедрой и директора филиала и переехал работать в Якутск, где при его непосредственном участии (от идеи до завершения строительства) был построен национальный медицинский центр. Умер Всеволод Иванович 10 мая 1999 г.

В 1988 г. кафедру возглавил Ю.И. Морозов. Под его руководством успешно продолжались исследования, начатые В.И. Астафьевым. Новым направлением стала разработка комплексного патогенетического лечения гнойных поражений мягких тканей у больных сахарным диабетом и методов его коррекции.

Коллектив преподавателей пополнился доцентом Л.И. Рыбалко, ассистентами Л.А. Садохиной, Ю.А. Бельковым, И.В. Нестеровым, К.А. Апарциным, Н.Г. Корниловым.

Любовь Ивановна Рыбалко перешла с кафедры факультетской хирургии в сентябре 1991 г., имея огромный опыт лечебной, педагогической и научной работы. Стала общественным деканом 5-го и 6-го курсов вечернего отделения. На кафедре госпитальной хирургии Любовь Ивановна проработала до 1998 года.

Людмила Александровна Садохина приступила к работе на кафедре в январе 1992 г. Научная работа имела своим итогом защиту кандидатской диссертации на тему «Исследования маркеров эндогенного синтеза оксида азота в биологических средах у больных перитонитом» в декабре 1998 г.

Юрий Анатольевич Бельков по окончании интернатуры стал общим хирургом, затем работал в областном сосудистом центре (с февраля 1982 г. - в должности заведующего отделением). В 1987 г. защитил диссертацию «Показания к поясничной симпатэктомии у больных с ишемическим синдромом нижних конечностей при облитерирующем атеросклерозе», научным руководителем которой была А.В. Серкина.

В январе 1992 г. Ю.А. Бельков возглавил отделение хирургии сосудов областной клинической больницы. В 1998 г. успешно защитил докторскую диссертацию на тему «Хирургия последствий травмы магистральных кровеносных сосудов», стал профессором кафедры.

Игорь Валентинович Нестеров после окончания интернатуры, с 1973 по 1976 гг., работал в Заларинской ЦРБ. В 1976 г. был принят в отделение гастрохирургии областной клинической больницы. В 1976-1980 гг. работал ассистентом кафедры. В ноябре 1987 г. И.В. Нестеров возглавил отделение колопроктологии областной клинической больницы. В 1992 г. Игорь Валентинович вернулся к преподавательской работе на кафедре и в 1995 г. защитил кандидатскую диссертацию на тему «Хирургическое лечение колостомированного больного». В 2004 г. стал лауреатом премии Правительства РФ в области науки и техники.

В феврале 1993 г. Юрий Иванович Морозов сложил с себя полномочия заведующего кафедрой.

23 февраля 1993 года кафедру госпитальной хирургии, а также институт хирургии ВСНЦ СО РАМН (с 1989 г.) возглавил доктор медицинских наук, профессор Е.Г. Григорьев. 
Работу на кафедре с 1994 по 2004 гг. совмещали профессор А.С. Коган, профессор В.А. Шантуров, доцент А.В. Таевский.

В сентябре 1995 г. коллектив кафедры пополнился ассистентом Константином Анатольевичем Апарциным. Окончивший с отличием институт, он был принят в аспирантуру кафедры госпитальной хирургии. Досрочно защитил в 1995 г. кандидатскую, а в 2001 г. - докторскую диссертацию.

В настоящее время К.А. Апарцин, будучи профессором кафедры, работает руководителем отдела медико-биологических исследований ИНЦ СО РАН и главным научным сотрудником Иркутского научного центра хирургии и травматологии.

В 1998 г. на кафедре стал работать ассистентом (по совместительству) Николай Геннадьевич Корнилов, который окончил ИГМИ в 1984 г. До 1999 г. - ординатор отделения оперативной гастроэнтерологии, с 2005 г. - заведующий отделением портальной гипертензии Иркутской областной клинической больницы, на протяжении 16 лет - главный хирург Иркутской области. В 1996 г. защитил кандидатскую диссертацию, в 2005 г. - докторскую. Преподавательскую работу совмещал с работой Министра здравоохранения Иркутской области. В настоящее время - профессор кафедры.

В 2005 г. после окончания аспирантуры и защиты кандидатской диссертации сотрудниками кафедры стали её ученики -Е.Е. Чепурных и А.Г. Макеев. В настоящее время доценты кафедры. Елена Евгеньевна успешно работает завучем кафедры, а Александр Геннадьевич - декан 5-го курса. В 2016 г. он избран заведующим кафедрой оперативной хирургии и топографической анатомии. На кафедре также работают ведущие хирурги областной клинической больницы, кандидаты наук: заместитель главного врача по хирургии П.И. Сандаков, заведующие отделениями С.А. Кыштымов, А.В. Новожилов, ординаторы А.И. Панасюк и С.Е. Григорьев, заведующая научным отделом экспериментальной хирургии ИНЦХТ д.б.н. С.А. Лепехова.

Несмотря на непрерывное малоэффективное реформирование высшего медицинского образования в стране, сотрудники госпитальной хирургической клиники (кафедра, Иркутский научный центр хирургии и травматологии, Иркутская областная клиническая больница), следуя традициям, заложенным Н.И. Пироговым, Ф.И. Иноземцевым, И.В. Буяльским и другими великими педагогами, учёными и хирургами, продолжают своё главное дело - лечить, учить, изучать.

\section{ЛИТЕРАТУРА \\ REFERENCES}

1. Григорьев Е.Г., Пак В.Е., Апарцин К.А., Садохина Л.А.Студенческий научный кружок-альтернатива бывшей субординатуры в подготовке врачей хирургов // Матер. науч.-практ. конф., посв. 50-летию кафедры госпитальной хирургии АГМА. - Благовещенск: АГМА, 2006. - C. 21-23.

Grigoryev EG, Pak VE, Apartsin KA, Sadokhina LA (2006). Student project group - an alternative to former pre-graduate internship in the training of surgeons [Studencheskiy nauchnyy kruzhok - al'ternativa byvshey subordinatury v podgotovke vrachey khirurgov]. Materialy nauchno-prakticheskoy konferentsii, posvyashchennoy 50-letiyu kafedry gospital'noy khirurgii AGMA, 21-23.

2. Григорьев Е.Г., Птиченко Ю.Л. Деятельность научно-лечебно-педагогического объединения // Акт. вопросы клин. медицины: Сб. докл. науч.-практ. конф., посв. 125-летию Иркут. гос. обл. Ордена «Знак Почёта» клин. больницы. - Иркутск, 1997. - С. 3-8.

Grigoryev EG, Ptichenko YL (1997). Activity of scientific, medical and educational association [Deyatel'nost' nauchno-lechebno-pedagogicheskogo objedineniya]. Aktual'nye voprosy klinicheskoy meditsiny: Sbornik dokladov nauchno-prakticheskoy konferentsii, posvyashchennoy 125-letiyu Irkutskoy gosudarstvennoy oblastnoy Ordena «Znak Pocheta» klinicheskoy bol'nitsy, 3-8.

3. Григорьев Е.Г., Решетникова Г.Н., Сякерский А.Г., Птиченко Ю.Л. Институт хирургии - научно-лечебнопедагогический комплекс // Бюл. ВСНЦ СО РАМН. 2001. - № 3. - C. 5-7.

Grigoryev EG, Reshetnikova GN, Syakerskiy AG, Ptichenko YL (2001). Institute of Surgery - scientific, medical and educational complex [Institut khirurgii nauchno-lechebno-pedagogicheskiy kompleks]. Bulleten' Vostocno-Sibirskogo naucnogo centra, (3), 5-7.

4. Григорьев Е.Г., Скворцов М.Б. История кафедры госпитальной хирургии Иркутского государственного медицинского университета // Акт. вопросы клин. медицины: Сб. докл. науч.-практ. конф., посв. 125-летию Иркут. гос. обл. Ордена «Знак Почёта» клин. больницы. - Иркутск, 1997. - С. 14-23.

Grigoryev EG, Skvortsov MB (1997). History of the department of hospital surgery of Irkutsk State Medical University [Istoriya kafedry gospital'noy khirurgii Irkutskogo gosudarstvennogo meditsinskogo universiteta]. Aktual'nye voprosy klinicheskoy meditsiny: Sbornik dokladov nauchno-prakticheskoy konferentsii, posvyashchennoy 125-letiyu Irkutskoy gosudarstvennoy oblastnoy Ordena «Znak Pocheta» klinicheskoy bol'nitsy, 14-23.

5. Григорьев Е.Г., Смирнов В.Л. Госпитальная хирургическая клиника: Иркутск, 1921-2001. - Иркутск: ИГМУ; НЦРВХ ВСНЦ СО РАМН, 2001. - 208 с.

Grigoryev EG, Smirnov VL (2001). Hospital surgical clinic: Irkutsk, 1921-2001 [Gospital'naya khirurgicheskaya klinika: Irkutsk, 1921-2001], 208.

\section{Сведения об авторах}

\section{Information about the authors}

Григорьев Евгений Георгиевич - член-корреспондент РАН, научный руководитель ФГБНУ «Иркутский научный центр хирургии и травматологии», заведующий кафедрой госпитальной хирургии ФГБОУ ВО «Иркутский государственный медицинский университет» Минздрава России (664049, г. Иркутск, мкр. Юбилейный, 100, тел.: 8 (3952) 40-78-09; е-таil: egg@iokb.ru)

Grigoryev Evgeniy Georgievich - Corresponding Member of RAS, Scientific Advisor of Irkutsk Scientific Center of Surgery and Traumatology, Head of the Department of Hospital Surgery of Irkutsk State Medical University (664049, Irkutsk, Yubileynyi, 100; tel.: +7 (3952) 40-78-09; e-mail: egg@iokb.ru) 